\title{
NOTAS SOBRE O ENTRELAÇAMENTO DO CONCEITO DE TÉCNICA E ANTISSEMITISMO NO PENSAMENTO DE MARTIN HEIDEGGER: REVISITANDO UMA POLÊMICA
}

\author{
Notes on the interlacement of the concept of Technique and Anti-semitism in Martin \\ Heidegger's thought: Revisiting a controversy
}

Maurício Fernandes

UFPI

\begin{abstract}
Resumo: Heidegger, sem dúvida, foi um dos maiores pensadores do século XX e escreveu uma das maiores obras filosóficas de tal século; porém, esta envergadura intelectual não o impedira de tomar decisões políticas reprováveis e nem mesmo blindou seu pensamento e obra do antissemitismo corrente, capilarizado e acentuado com o advento da subida ao poder do nacional-socialismo na Alemanha. O que pode levar um pensador da envergadura intelectual de Heidegger, já conhecido à época por sua opus magna Sein und Zeit, à de modo consciente, radical e determinado colocar sua própria filosofia à serviço do nacional-socialismo e a cultuar a figura de um dos maiores facínoras da história? Neste trabalho procuraremos compreender o fenômeno tecnocientífico como um elemento a partir do qual Heidegger enxerga a "grandeza" do nacional-socialismo. Procuramos apontar para os elementos presentes nas análises de Heidegger sobre Técnica e ciência que se constroem gradativamente direcionando-se para o antissemitismo e atrelamento de seu projeto filosófico com o nazismo. Pretendemos uma contribuição á uma compreensão do envolvimento de Heidegger com o nacional-socialismo a partir de uma análise de seu pensamento sobre o fenômeno tecnológico.
\end{abstract}

Palavras-chaves: Heidegger. Mundanidade. Técnica. Nazismo.

\begin{abstract}
Heidegger was, undoubtedly, one of the greatest thinkers of the twentieth century, and wrote one of the greatest philosophical works of that century: Sein und Zeit. However, this intellectual breadth did not prevent him from taking reprehensible political decisions, and did not even shield his thinking and work from the current anti-Semitism, branched and accentuated by the advent of the rise to power of National Socialism in Germany. What can lead a thinker of Heidegger's intellectual scope consciously, radically and determinedly to put his own philosophy at the service of National Socialism and to worship the figure of one of the greatest murderers in history? In this work, we will try to understand the techno-scientific phenomenon as an element from which Heidegger sees the "greatness" of National
\end{abstract}


Socialism. We seek to point to the elements present in Heidegger's analyzes of technique and science, which are gradually being directed towards anti-Semitism and the linkage of his philosophical project with Nazism. We intend to contribute to an understanding of Heidegger's involvement with National Socialism from an analysis of his thinking on the technological phenomenon.

Keywords: Heidegger. Bodenständigkeit. Technique. Nazism.

\section{INTRODUÇÃO}

Acho que é útil não nos esquecermos de que Heidegger não foi apenas um nazi, foi alguém que tentou desesperadamente tomar a dianteira no movimento nazi, fazer esse movimento apoiar as suas ideias filosóficas. Heidegger queria ser o Führer intelectual da Alemanha, o dirigente ideológico da Alemanha, mais ou menos na linha de Fichte, o filósofo que tinha sido a expressão da consciência da nação. Heidegger levou esse projecto muito a sério, pensou que Hitler Ihe daria uma oportunidade; enganou-se, e ao fim de um ano estava desiludido. Não acho que isso, só por si, seja assim algo tão terrível, qualquer pessoa poderia ter tido uma ambição destas. Mas acho que o que as pessoas têm razão em não lhe poderem perdoar é o facto de ter mentido sobre o assunto durante 40 anos.

Acho que, para alguém que esteve tão ligado aos nazis, não se pronunciar de modo algum sobre o destino dos judeus é inadmissível. Portanto, não acho que se possa dizer o que quer que seja de bom acerca do carácter moral de

Heidegger; mas, por outro lado, retiramos muitas ideias de livros escritos por pessoas moralmente horrorosas, e vamos continuar a retirar muito dos livros de

Heidegger, ainda que ele tenha sido um homem horroroso. O que eu não entendo é a ideia de que a acção política de Heidegger tenha influenciado a sua filosofia, e parece-me que diversos grandes filósofos cometeram erros políticos estúpidos: Bertrand Russel cometeu erros políticos estúpidos, Sartre cometeu erros políticos estúpidos. A tentativa de aproveitar o movimento nazi foi um erro político estúpido, e a sua posterior mentira a seu respeito foi má.

Richard Rorty

Nas linhas que se seguem trataremos, como disse Richard Wolin", de "ossos no armário". Temos consciência da amplitude que a polêmica referente ao envolvimento de Heidegger com o nacional-socialismo atingira atualmente, e também da extensa literatura produzida sobre tal polêmica de ambos os lados, tanto em sua defesa, quanto em suas

\footnotetext{
${ }^{1}$ Cf. WOLIN, R. The Seduction of Unreason: The Intellectual Romance with Fascism from Nietzsche to Postmodernism. New Jersey: Princeton University Press, 2004.
} 
exposições. E sabemos que após a publicação dos Cadernos Negros [Schwarze Hefte] (2014) tal polêmica potencializou-se. Porém, nosso eixo neste momento será a estruturação do conceito de técnica e a importância deste na aproximação de Heidegger à ideologia do nacionalsocialismo.

Pretendemos aqui, a partir de uma revisão bibliográfica de textos referenciais, uma aproximação ao conceito de técnica no pensamento de Heidegger, e seu subsequente e gradativo entrelaçamento à conteúdos fortes da ideologia do nacional-socialismo. Nas linhas que se seguem encetaremos uma via de compreensão do fenômeno tecnológico enquanto link constitutivo de aproximação entre o pensamento de Heidegger e a ideologia nazista. Compreendemos ser a questão da técnica um ponto fundamental do pensamento de Heidegger, que se espraia por sua trajetória intelectual, e elemento importante em sua gradativa aproximação e adesão ao nazismo. Partiremos não de uma "acusação", mas do fato claro e explícito do envolvimento consciente e determinado de Heidegger com o nazismo. Heidegger foi nazista, e isto não se trata de uma "acusação" infundada, mas da constatação de um fato, que de espécie alguma se presta a depreciação do pensamento de Heidegger.

É preciso superar as polarizações, de ambos os lados existem elementos e argumentos válidos e é preciso compreender que estamos diante de uma polêmica que pode sim colaborar para uma releitura e compreensão mais enriquecida da obra de tal pensador. De um lado as acusações em tom depreciativo, tanto quanto as defesas baseadas em argumentos que apontam uma má interpretação e/ou desconhecimento da obra de Heidegger em profundidade, se constituíram como chavões vazios que acabam por impedir uma releitura séria e rigorosa da obra de Heidegger.

Heidegger foi nazista, e permaneceu nazista mesmo após a dissolução do partido, mas a recusa ao estudo de sua obra em detrimento deste fato em sua vida é uma atitude arrogante e pretensiosa; assim como a defesa do indefensável. Não há como borrar esta página da história, não se apaga este fato na vida deste pensador e de todos os outros que, na história do Ocidente tiveram escolhas errôneas em suas vidas; porém, nenhuma dessas pode obliterar o peso da obra filosófica de Heidegger no Ocidente e ao contrário, devemos nos empenhar, como apontou Günter Figal, em uma releitura da obra de Heidegger, para uma compreensão mais rigorosa e menos ingênua acerca dos limites de seu pensamento e envolvimento com o nazismo. 
Não pretendemos tocar no antissemitismo de Heidegger como forma de vilipendiar a imagem de um dos maiores pensadores do século passado, mas sim, no intuito de compreender a evolução interna de seu conceito de técnica e, consequentemente, também de seu pensamento acerca do nacional-socialismo; a partir da qual defenderemos a tese de que o próprio conceito de técnica acabou por se constituir como vínculo entre seu pensamento e a ideologia nazista, e elemento motivador de seu afã em colocar sua filosofia a serviço do Terceiro Reich e também da evolução de seu antissemitismo.

\title{
1 UM EXCURSO SOBRE HEIDEGGER E O NAZISMO: O RESSURGIR DE UMA POLÊMICA
}

\begin{abstract}
Can we be assured, however, that there was never any echo of Evil in it? The diabolical is not limited to the wickedness popular wisdom ascribes to it and whose malice, based on guile, is familiar and predictable in an adult culture. The diabolical is endowed with intelligence and enters where it will. To reject it, it is first necessary to refute it. Intellectual effort is needed to recognize it. Who can boast of having done so? Say what you will, the diabolical gives food for thought.
\end{abstract}

Lèvinas, As if Consenting the Horror.

Em primeiro de maio de 1933 Martin Heidegger filiara-se formalmente ao partido nacional socialista - NSDAP [Nationalsozialistische Deutsche Arbeiterpartei]. Tal fato surtira estupefação por parte de estudantes e amigos acerca dos reais motivos que levaram um dos maiores pensadores do século XX a tomar uma decisão tão equivocada.

Desde de 1987, com a publicação da obra de Victor Farias intitulada Heidegger et le nazisme, uma polêmica se alastrou à sombra do envolvimento de Heidegger com o nacionalsocialismo, provocando polarizações entre acusações e defesas efusivas, gerando uma polêmica que se agravou com a difusão midiática, que tratou de mostrar o caráter ambíguo de tal pensador em solo e língua francesa². Em 2014, Peter Trawny, à época diretor do Instituto

\footnotetext{
${ }^{2}$ A própria escolha de Farias em publicar sua obra em solo francês possui como fundamento a exposição deste aspecto à época obscuro em relação ao pensamento de Heidegger e seu envolvimento com o nacional-socialismo. Após o término da guerra foi instaurado em solo alemão o processo de desnazificação e junto a tal processo houve um afastamento das funções docentes, bem como uma deflação da influência intelectual de Heidegger na Alemanha, o que se manteve em solo francês. Desta 
Martin Heidegger em Wuppertal, foi responsável pela edição e publicação dos Cadernos Negros [Schwarze Hefte], páginas nas quais ecoa a voz do próprio Heidegger mostrando explicitamente seu envolvimento com o nazismo não enquanto ideologia de um partido, mas enquanto algo enraizado, encarnado e capilarizado no cotidiano das relações e que acabara por irromper em sua obra, em seu próprio projeto filosófico, sendo este posto à serviço do "movimento" [Deutschen Bewegung].

Em pouco tempo após a publicação da obra de Farias, e da exposição dos elementos ínsitos na obra de Heidegger que denunciavam seu antissemitismo e sua filiação livre, espontânea e determinada ao nacional-socialismo, bem como seu silêncio sepulcral acerca deste, criou-se um verdadeiro "tribunal" sobre "o caso Heidegger". Assim, tal autor viu-se, de um lado, acusado veementemente e "forçado" a retratar-se por suas escolhas e decisões políticas em um dos períodos mais nefastos da história ocidental; e de outro, defendido efusivamente por intelectuais como Francois Ferdier, Pierre Aubenque e mais recentemente por Friedrich-Wilhelm von Herrmann e Francesco Alfierri.

Heidegger, sem dúvida alguma, foi um dos maiores pensadores do século XX e escreveu uma das maiores obras filosóficas de tal período, a saber: Ser e Tempo [Sein und Zeit], porém, esta envergadura intelectual não o impedira de tomar decisões políticas depreciáveis, e tampouco Ihe fornecera elementos para blindar seu pensamento e obra da ideologia e do antissemitismo propagado e levado ao extremo pelo nacional-socialismo à época. "Heidegger não só adotou essas ideias antissemitas, mas as processou filosoficamente, falhando em imunizar seu pensamento dessas tendências" como afirma Peter Trawny em entrevista ao The Guardian ${ }^{4}$.

No ano seguinte à publicação da obra de Victor Farias, François Ferdier publicou uma obra intitulada Heidegger: Anatomie d'un scandale, defendendo Heidegger, e tipificando as acusações de Farias como "pseudo-acontecimentos" de caráter "anti-heideggerianos" (FÉDIER, 1988). E neste clima de polarizações tal polêmica manteve-se como uma sombra seguindo o pensamento de Heidegger, e de certa forma, fora agravada pelo silêncio atroz que

forma, Farias publica sua obra em um horizonte marcado pela vitalidade do pensamento de Heidegger na França, um aspecto indiciário da amplitude da polêmica que a publicação de sua obra iria alcançar.

${ }^{3}$ Como denominavam os próprios nazista ao partido, seguindo o exposto por Hitler no Mein Kampf.

${ }^{4}$ Heidegger didn't just pick up these antisemitic ideas, he processed them philosophically - he failed to immunise his thinking from such tendencies. Cf. TRAWNY Apud OLTERMANN, The Guardian, 13 março de 2014. 
acompanhou o filósofo desde o período do pós-guerra até o túmulo. Silêncio este, questionado por vários intelectuais, porém, sem resposta por parte de tal pensador ${ }^{5}$.

A partir da publicação dos Cadernos Negros [Schwartze hefte] em 2014 esta polêmica ressurge, agora sob o prisma de serem escritos em primeira pessoa, e torna explícito o envolvimento de Heidegger com o nacional-socialismo para além dos marcos "suspeitos" anteriormente. Ou seja, Heidegger não apenas filiara-se ao partido nacional-socialista (Nationalsozialistische Deutsche Arbeiterpartei - NSDAP) durante o período de ascensão política e institucional deste, mas de forma consciente e determinada seguiu filiado para além da dissolução deste em 1945, não excluindo de seu jargão poético-filosófico no pós-guerra conceitos e expressões tipicamente oriundos ou utilizados pela ideologia nazista. Heidegger fora nazista. É um fato, talvez não conhecido para fora do solo alemão, onde por "posturas tendenciosas" ou "ingenuidade" se seguiram traduções que insistiram na deflação, e mesmo na omissão de aspectos explicitamente fascistas presentes nos textos de Heidegger no período de ascensão do partido e da tomada de poder por Hitler, período este marcado por sua permanência na reitoria da Universidade de Freiburg.

$\mathrm{O}$ antissemitismo de Heidegger e seu envolvimento com o nazismo tornam-se evidentes em muitas das elaborações filológico-filosóficas de sua obra, quer seja em cartas às pessoas próximas, em homenagens as $\mathrm{SA}^{6}$, proferindo discursos em tom propagandista, o apreço pela figura do Führer $^{7}$, a identificação do processo de maquinação com o judaísmo

\footnotetext{
${ }^{5}$ Herbert Marcuse foi um dos primeiros intelectuais a suspeitar da existência de elementos ínsitos na obra de Heidegger que indicariam sua conversão ao nazismo. E até mesmo chegou a procura-lo pessoalmente aguardando o pronunciamento do ex-mestre que o havia ensinado filosofia de 1928 a 1932; porém, retornara frustrado aos EUA diante do silêncio de Heidegger no sentido de uma possível retratação. Cf. MARCUSE, Herbert. Heidegger's Politics: An Interview. In: Pippin, Robert (ed.), Marcuse: Critical Theory and the Promise of Utopia. Bergin and Garvey, South Hadley, M. A, 1988, p. 99.
}

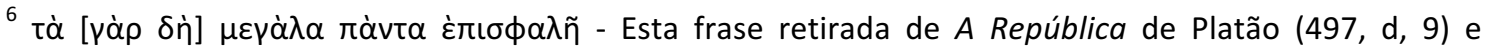
pronunciada em uma noite no dia 07 de maio de 1933 reflete a grandeza, mas também a periculosidade do pensamento. Em seu discurso de posse da Reitoria da Universidade de Freiburg Heidegger terminou proferindo tal sentença: "Alles Große steht im Sturm!" A partir de um lapso linguístico-filológico intencional Heidegger transforma a sentença platônico-socrática em um emblema do destino alemão evocado no texto de seu discurso, e uma saudação à um amigo e a um grupo específico. Ao forçar uma

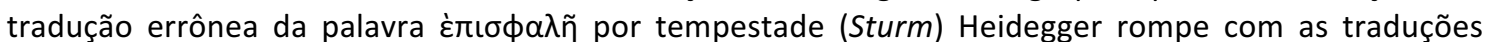
correntes que traduziram tal palavra por Fallen. Mas Heidegger bramiu: "Alles Große steht im Sturm!". Sendo tempestade (Sturm) aqui uma alusão às Sturmabteilung (SA) principal grupo de apoio a sua ascensão à Reitoria e de cujo general Ernst Röhm possuía a amizade e admiração.

${ }^{7}$ Durante uma visita a Jaspers este provocou Heidegger perguntando-lhe como alguém tão ignorante como Hitler poderia governar a Alemanha [Wie Soll en so ungebilteter Mensch wie Hitler Deuschland regieren?], ao que Heidegger respondeu: "Educação é completamente indiferente, olhai apenas para 
mundial, ou mesmo em sua classificação como mitläufer ${ }^{8}$ obtida na comissão de desnazificação. Porém, o que fica aparente é que este fato (o antissemitismo e filiação ao nazismo) em Heidegger seguiu sendo conhecido em solo alemão, ao passo que permanecera, sob certo tempo, desconhecido ou sendo "suspeito" para outras nacionalidades.

Em uma entrevista em 08 de novembro de 2014 ao Le Monde, Jürgen Habermas, ao ser questionado sobre os impactos da descoberta e posterior publicação dos Cadernos Negros afirma que por si só tais escritos de Heidegger já são esmagadores, e que não fora recebida como uma surpresa em solo alemão a ligação deste pensador com o nacional-socialismo. Habermas afirma que:

[...] desde a publicação das conferências de Heidegger de 1935, Introdução à Metafísica, nenhum leitor alemão não poderia mais confundir a impregnação fascista do jargão heideggeriano. Ele foi um nazista. Mas o mais terrível para nós, estudantes que foram uma vez expostos a sua influência, foi o fato de Heidegger jamais ter publicamente se distanciado de seu passado nazista - nem mesmo quando seu ex-aluno Herbert Marcuse incitou a fazê-lo, alguns anos depois da guerra ${ }^{9}$ (HABERMAS, 2014).

Em outras palavras, desde a publicação de Introdução à Metafísica em 1935 em solo alemão tornara-se impossível não reconhecer os elementos indiciários da relação ainda viva de Heidegger com conteúdos da ideologia nazista. Para Habermas, desde a tradução de Carta sobre o Humanismo [Brief über Humanismus] em solo francês houve uma deflação e atenuação dos elementos fortes e explícitos no jargão heideggeriano.

O que li sobre os Cadernos Negros por meio de resenhas é em si esmagador, mas não é realmente uma surpresa. A recepção de Heidegger na França após 1945, foi desde o princípio, desde a tradução de Jean Beaufret da Carta ao Humanismo (Aubier, 1957), deploravelmente tendenciosa - bem elaborada para o lado de Heidegger, e ingênua para o lado dos leitores franceses! Mas também tem a

suas maravilhosas mãos! "Bildung ist Ganz gleichgültige, Sehen Sie nur seine wunderbaren Hände an!". Cf. JASPERS, 1977, p. 101; 1990, p. 105).

${ }^{8} \mathrm{O}$ termo Mitläufer denotava uma das mais baixas classes de periculosidade no nazismo, ficando acima apenas daqueles que não possuíam envolvimento. Literalmente significa "partidário", ou "seguidor", aquele que participara passivamente sem oposição, quer seja por algum interesse ou por apenas estar no grupo. Heidegger recebera este título em março de 1949 por parte da Comissão Estadual de Purificação Política como parte do processo de desnazificação no pós-guerra.

9 [...] depuis la publication des conférences de Heidegger datant de 1935, L'Introduction à la métaphysique (Gallimard, 1967), nul lecteur germanophone ne pouvait plus se méprendre sur l'imprégnation fascistoïde du jargon heideggerien. Il a bien été un nazi. Mais le plus terrible pour nous, les étudiants qui tous étions jadis exposés à son influence, fut le fait que Heidegger n'a jamais publiquement pris ses distances avec son passé nazi - même pas quand son ancien élève Herbert Marcuse l'a incité à le faire, quelques années après la guerre. 
ver com nosso problema europeu: com a pluralidade e desconhecimento recíproco de nossas línguas ${ }^{10}$ (HABERMAS, 2014).

Atualmente, a partir da publicação dos Cadernos Negros em 2014, esta polêmica ganha novamente força e vitalidade. Porém, diante da constatação do antissemitismo de Heidegger e de seu claro envolvimento com o nazismo, uma dúvida persiste, e cremos ser fundamental o debate acerca deste caráter ainda polêmico no sentido de um direcionamento acerca das pesquisas da obra de tal filósofo: O que faremos? Rasgaremos Ser e Tempo? Nos recusaremos a ler Heidegger?

Em outubro de 1987, em meio a uma aula na Sorbonne, Pierre Aubenque fora surpreendido com a súbita retirada de um estudante da sala ao ouvir o nome de Heidegger, estudante este ao qual dedicara seu ensaio Encore Heidegger et le nazisme (1988). Obviamente, o debate sobre esta polêmica acerca do filósofo de Merßkirch, não deve se prestar a uma proposta improdutiva e empobrecedora de renúncia à obra de Heidegger frente à constatação de seu antissemitismo e envolvimento com o nazismo.

A censura absoluta do pensamento de Heidegger baseada em sua profundamente errônea afiliação política não é apenas uma resposta inadequada - ela perde uma oportunidade de compreender melhor o papel que a tecnologia desempenhou em promover a ideologia nazista ${ }^{11}$ (GUNKEL, 2014, p. 08).

Mas antes, nos alinhamos à postura de Lévinas, que apesar de sentir na própria pele o peso desta escolha tão deplorável de seu mestre (assim como outros estudantes judeus que estiveram à influência de Heidegger), não deixou ofuscar a importância filosófica de Ser e Tempo.

Apesar do horror que um dia veio associar-se ao nome de Heidegger - e que nada poderá dissipar - nada conseguiu desfazer em meu espírito a convicção de que Sein und Zeit, de 1927, é imprescritível, ao mesmo título que alguns

${ }^{10}$ Ce que j'ai lu sur les "Cahiers noirs " dans les recensions est à soi seul accablant; mais il n'y a pas vraiment de surprise. La réception de Heidegger en France après 1945 a été dès le début, dès la traduction par Jean Beaufret de la Lettre sur I'humanisme (Aubier, 1957), déplorablement biaisée - bien jouée du côté de Heidegger, naïve du côté des lecteurs français! Mais cela aussi a à voir avec notre problème européen: avec la pluralité et la méconnaissance réciproque de nos langues.

${ }^{11}$ [...] unalloyed censure of Heidegger's thought based upon his deeply flawed political affiliation is not only an inadequate response - it misses an opportunity to understand better the role technology played in facilitating Nazi ideology. 
outros livros eternos da história da filosofia - ainda que discordantes entre $\mathrm{si}^{12}$. (LÉVINAS, 1997, pp. $252-253$ ).

Não podemos jogar fora a criança junto com o banho. Heidegger, apesar de sua errônea e péssima escolha política à época, escreveu uma das maiores obras de filosofia do século XX; porém, de igual modo, não mais podemos nos furtar a constatação de seu antissemitismo e ler suas obras com lentes ingênuas, é preciso extrair o que há de potencialidade, mais também, com rigor e sinceridade intelectual apontar suas insuficiências.

\section{SOBRE O CONCEITO DE TÉCNICA NO PENSAMENTO DE HEIDEGGER}

\subsection{Martin Heidegger: Um pensador da técnica.}

Heidegger é um pensador da técnica. Um pensador referencial acerca deste fenômeno em seu aporte filosófico. A questão sobre o fenômeno tecnológico apresenta-se como eixo nodal do pensamento de Heidegger, e pode-se argumentar que tenha se tornado um dos conceitos mais importantes e caros à contribuição filosófica de tal autor, na qual se expressa uma evolução interna na arquitetônica de seu pensamento sobre o conceito de técnica, e principalmente, acerca da técnica moderna (BORGMANN, 2005, p. 420).

O pensar sobre a técnica torna-se gradativamente um ponto recorrente no pensamento de Heidegger. Tal conceito se desenvolve a partir de uma compreensão neutra do conceito de técnica arraigada em uma visão negativa acerca da mesma, decorrente de um romantismo que evocava a terra, o orgânico e as forças elementares [Grundkräfte] em enfrentamento ao racionalismo e às perspectivas de um humanismo universal tal como proposto pelo lluminismo.

Assim, houve uma apreciação do orgânico em detrimento ao racional. De um lado, a vida enquanto força dinâmica e em constante mudança; e de outro a razão e o cálculo. A dicotomia entre orgânico e racional se mostrou vívida no pensamento de Heidegger sobre a técnica, e principalmente sobre técnica moderna como expresso nos Cadernos Negros, onde Heidegger coloca a organização e ao cálculo em contraposição ao orgânico. "A técnica e sua irmã gêmea - a 'organização' - avançam ambas em sentido contrário a todo o 'orgânico' e

\footnotetext{
${ }^{12}$ [...] Malgré toute l'horreur qui vint um jour s'associer au nom de Heidegger - et qui rien n'arrivera à dissiper - rien n'a pu défaire dans mon esprit la conviction que Sein und Zeit de 1927 est imprescriptible, au même titre que les quelques autres libres éternels de l'histoire de la philosophie - fussent-ils en désaccord entre eux.
} 
obedecendo a sua essência, conduzem a seu final próprio: o esvaziamento e o enfraquecimento por meio delas ${ }^{13 \prime \prime}$ (HEIDEGGER, 2014, p. 364).

Uma perspectiva romântica sobre a realidade moldou as concepções acerca do fenômeno tecnocientífico em solo alemão, que se caracterizou por uma visão extremamente negativa sobre este; e consequentemente, a grande ameaça que se apresentava desde os alvores do século XVIII era o avanço tecnocientífico.

Rapidamente a concepção de técnica passa a ser algo como uma força "devoradora de homens" [Menschenfresser], e destruidora de uma natureza bucólica que permeava a Alemanha, em pouco tempo as paisagens bucólicas deram lugar às minas de carvão e às indústrias. Este é o background a partir do qual pensadores como Oswald Spengler, Ernst Niekisch e Ernst Jünger dentre outros irão construir suas visões acerca do fenômeno tecnológico, e a partir dos quais Heidegger também será influenciado.

O conceito de técnica é desenvolvido por Heidegger já em Ser e Tempo (1927), a partir da preocupação com a constituição ontológica do Dasein em consonância com o mundo no qual se encontra. Daí os conceitos de "manualidade" [Vorhandenheit] e "estar à mão" [Zuhandenheit] serão importantes para uma compreensão da totalidade instrumental constitutiva do mundo no qual o próprio Dasein é e está lançado. No marco ontológicofenomenológico de Ser e Tempo Heidegger não está preocupado com um conceito de técnica específico, mas antes, procura compreender a partir de uma totalidade instrumental a constituição do mundo.

Há um comentário de Heidegger em 1934, presente em sua edição das obras completas sob o número 38 intitulada Logik als die Frage nach dem Wesen der Sprache na qual aponta para a origem de uma técnica "que é mais do que o domínio dos instrumentos e das máquinas, que tem antes o seu significado fundamental numa relação modificada do homem com o mundo ${ }^{14 "}$ (HEIDEGGER, 2008, p. 221).

Em Heidegger o conceito de técnica se apresenta primeiramente atrelado à sua crítica ao caráter instrumental desta; se apresentando em dois âmbitos primários distintos, como aponta Fragoso (2012):

${ }^{13}$ Die Technik und ihre Zwillingsschwester - die "Organisation" - beide das Gegenlaufige zu allem "Organischen" - treiben ihrem / Wesen nach auf ihr eigenes Ende, die Aushohlung durch sich selbst, zu.

${ }^{14}$ [...] die mehr ist als die Beherrschung der Werkzeuge und der Maschinen, die ihre fundamentale Bedeutung vielmehr in einer veränderten Weltstellung des Menschen hat. 
A crítica da concepção instrumental da técnica se apresenta em Heidegger de dois modos distintos: em Ser e Tempo, a técnica é pensada como elemento constitutivo do mundo, estrutura fundamental do ser-aí (Dasein); em A Questão da Técnica, ela é uma "forma do desencobrimento" ou um "destino do desencobrimento" que rege o homem e seu "fazer" (p. 512). [Grifos do autor].

Heidegger evoca o próprio conceito de techné dos gregos, enquanto desvelamento; enxergando já o caráter mais essencial da técnica moderna: o processo de dominação gradativa e massiva do homem sobre o mundo e sobre si mesmo, que possui como núcleo tão somente a maquinação [Machenschaft], a matematização, o cálculo, a automatização e disposição de tudo, incluindo-se o próprio homem.

\subsection{A leitura da obra de Ernst Jünger}

A leitura da obra de Ernst Jünger deixou impressões expressivas no pensamento de Heidegger sobre a técnica, e dessa forma, podemos coadunar com o exposto por Michael Zimmerman (1990, p. 18) que os textos de Jünger formam um link entre o pensamento de Heidegger e seu engajamento com o nacional-socialismo ${ }^{15}$, ao mesmo tempo em que direciona uma estruturação do conceito de técnica para além dos marcos da ontologia fundamental de Ser e Tempo (1927) ganhando nova envergadura na década de 1930 com as leituras de A Mobilização Total [Die Totale Mobilmachung] (1930) e O Trabalhador [Der Arbeiter] (1932). A leitura de tais obras abriu horizontes para o desenvolvimento do conceito de técnica para um âmbito ainda não esboçado por Heidegger.

Aquilo que Ernst Jünger pensa, nos conceitos de dominação e forma do trabalhador, e que ele vê à luz desses pensamentos, é o domínio universal da vontade de poder no interior da história vista planetariamente. É nessa realidade [Wirklichkeit] que hoje se encontra tudo, quer se chame comunismo, fascismo ou democracia mundial. É a partir dessa realidade da vontade de poder que eu comecei a ver, já nessa época, o que ád $^{16}$. (HEIDEGGER, 1985, p. 485) [Grifo do autor].

\footnotetext{
${ }^{15}$ Junger's writings, I contend, form a link that mediates between Heidegger's thought, on the one hand, and his engagement with National Socialism, on the other.

${ }^{16}$ What Ernst Jünger thinks with the thought of the rule and shape of the worker and sees in the light of this thought, is the universal rule of the will to power within history, now understood to embrace the planet. Today everything stands in this historical reality, no matter whether it is called communism, or fascism, or world democracy. From the vantage point of this reality of the will to power I saw even then what is.
} 
A leitura da obra de Jünger propiciou para Heidegger uma compreensão do caráter novo e perigoso de um fenômeno que se levantava à frente do homem, a saber: a técnica moderna. A partir desta leitura o horizonte de compreensão do fenômeno tecnológico no pensamento de Heidegger encontra um direcionamento para além dos contornos delineados em Ser e Tempo (1927). Não há mais uma a pretensão de resolução da questão do ser mediante a fenomenologia da facticidade, mas uma compreensão do fenômeno tecnológico como característico de nossa época, concentrando em si mesmo, a uma só vez, o caráter perigoso e salvífico. É preciso compreender a essência da técnica, no que há de mais perigoso e procurar expurgá-la. Assim, por alguns elementos em construção a época em seu pensamento deixa-se intoxicar com o antissemitismo. Pois a essência da técnica moderna para Heidegger, expressa nos Cadernos Negros, residia na "maquinação" como princípio do judaísmo global.

O período em que Heidegger lera as obras de Jünger coincidem com sua subida à Reitoria da Universidade de Freiburg. Um período turbulento, de 1933 a 1934, no qual passara Heidegger dez meses como Reitor. Período de maturação do conceito de técnica, que abandona sua condição de uma essência abstrata para irromper na justificação do antissemitismo ao atrelar a essência da técnica moderna com acusações espúrias contra os judeus. A leitura de Jünger influenciou Heidegger para além deste marco de 1933/1934.

A forma (Gestalt) do trabalhador se torna para Heidegger uma possibilidade de manifestar o que caracteriza nossa contemporaneidade mediante a técnica, ou seja, o domínio sobre todos os âmbitos possíveis da existência.

A questão da Gestalt significa a necessidade de dar forma a uma existência impactada pela ameaça da falta de forma emergente da tecnologia e da convulsão social. Para Heidegger, no entanto, a crítica cultural dos conservadores falhou em compreender as raízes da falta de forma no destino extremamente metafísico do Ocidente. Consequentemente, um conceito de forma, como Gestalt, tem que ser conquistado a partir da desconstrução da metafísica como efetuada pela tecnologia ${ }^{17}$ (RADLOFF, 2007, p. 03).

${ }^{17}$ The question of gestalt signifies the necessity of giving form to an existence impacted by the threat of formlessness emerging from technology and social upheaval. According to Heidegger, however, the cultural critique of the conservatives failed to grasp the roots of formlessness in the very metaphysical destiny of the West. Consequently, a concept of form, as gestalt, has to be won from the deconstruction of metaphysics as realized in technology. 
O conceito de técnica adquire nova tessitura a partir da leitura que Heidegger fez da obra de Ernst Jünger, e principalmente a obra Der Arbeiter (1932), na qual teve plena convicção de que a técnica moderna agora se apresentava como modo pelo qual o homem domina o mundo e a si mesmo no sentido da disposição (Gestell). Desta forma, o conceito de técnica abandona sua condição como desenvolvida na fenomenologia da facticidade e passa a se compreender como o próprio destino do ser, sua manifestação "epocal", como afirma Loparic (1990):

Com o tempo Heidegger passou "a ver na técnica não uma explicitação interpretativa da tradição, mas uma manifestação "epocal" do próprio Ser [...] Desde então, um dos principais problemas da sua filosofia passou a ser a compreensão da transformação radical do mundo, em particular, a transformação tecnológica e o modo de lidar com ela. Esse problema urgia porque Heidegger percebera, ao mesmo tempo, o caráter avassalador, demoníaco, da técnica (p. 201).

A partir da influência da leitura da obra de Jünger ocorrem dois direcionamentos no desenvolvimento de técnica no pensamento de Heidegger. $O$ primeiro em relação à sua compreensão neutra e essencialista de tal fenômeno, que mesmo continuando essencialista manifesta-se agora no campo da política, no qual tal fenômeno irrompe com um caráter de perigo; e o segundo, em relação a aproximação deste conceito de técnica, agora político e encorpado com os conteúdos de uma influência antissemita em Jünger com a ideologia do nacional-socialismo.

\section{O DESENVOLVIMENTO do CONCEITO DE TÉCNICA E A APROXIMAÇÃO À IDEOLOGIA NACIONAL-SOCIALISTA}

O conceito de técnica na arquitetônica do pensamento de Heidegger sofreu um desenvolvimento gradativo, no qual se somam elementos que o levam de uma concepção de técnica para além de seu caráter instrumental, para uma compreensão do perigo da técnica moderna, e também da própria modernidade. Assim, o conceito de técnica se desenvolve gradativamente passando a abranger preocupações políticas de Heidegger. Desta forma, passa a enxergar no avanço da técnica e ciência modernas a expressão de uma marcha dos EUA e Inglaterra sobre o mundo, a Europa e a Alemanha; assim, irá encontrar no discurso do nacional-socialismo uma forma de enfrentamento a tal avanço. 
O nazismo passou a representar a possibilidade de instauração de uma comunidade do trabalho [Arbeitsgesellschaft] de caráter nietzsche-jüngeriano e de restauração das autênticas origens do povo alemão.

\begin{abstract}
Heidegger sustentou que o nacional-socialismo iria restaurar a Alemanha às suas origens autênticas, tornando assim possível uma nova relação com o trabalho por parte do povo alemão. Já no fim de sua carreira Heidegger não apenas continuou a acreditar que a visão de Jünger foi a melhor descrição do estágio final tecnológico na história da metafísica producionista, bem como sustentou que sua própria versão do nacional-socialismo realizou a promessa genuína para o movimento através do estágio tecnológico da história ocidental ${ }^{18}$ (ZIMMERMAN, 1990, p. 08).
\end{abstract}

Assim, na medida em que desenvolvera seu conceito de técnica, paralelamente, desenvolvia também sua simpatia pela ideologia do nacional-socialismo. Podemos observar que na medida em que se desenvolve o conceito de técnica no pensamento de Heidegger, este, por sua vez, desenvolve também sua aproximação gradativa, sólida e significativa com os ideais nazistas.

\title{
3.1 Horizontes de transição e entrelaçamento do conceito de técnica e do antissemitismo no
} pensamento de Heidegger

Heidegger desenvolve seu conceito de técnica a partir de horizontes de transição que irão gradativamente aproximá-lo da ideologia do nacional socialismo. Não resta dúvida que as ideias de Heidegger acerca do fenômeno tecnológico foram importantes em sua atração à ideologia do nacional-socialismo. Aos poucos o que em Heidegger era do campo da abstração, meditação e do âmbito do Dasein, fora transmutando-se e encontrando uma roupagem prática e institucionalizada com a revolução, com a tomada do poder por Hitler [Machtergreifung] e instauração do nacional-socialismo como possibilidade de supressão da técnica moderna e também como possibilidade de encontro do indivíduo com o que há de “essencial” na missão alemã.

\footnotetext{
${ }^{18}$ Heidegger maintained that National Socialism would restore Germany to its authentic origins, thereby making possible a new relationship to work on the part of the German Volk. To the end of his career, Heidegger not only continued to believe that Junger's vision was the best description of the final, technological stage in the history of productionist metaphysics, but also maintained that his own version of National Socialism had held out genuine promise for movement beyond the technological stage of Western history.
} 
Heidegger escreveu vários ensaios na década de 1930 sobre "a questão da tecnologia", e não há dúvida de que suas opiniões sobre o assunto eram importantes em sua atração inicial ao nacional-socialismo. Além disso, como os intelectuais da direita cujo entusiasmo pela tecnologia não conhecia limites, Heidegger acreditava que os alemães tinham uma missão especial para combinar técnica [Technik] e cultura [Kultur]. Por algum tempo ele pensou que os nazistas cumpririam esta missão especial. Quando concluiu que o hitlerismo continuaria o processo de longo prazo de dominação ocidental sobre o "ser", ele se retirou da política e caiu em desgraça com os nazistas. Seu desgosto fundamental pela tecnologia moderna tornou-se óbvio $^{19}$. (HERFT, 1998, p. 109).

Assim como os intelectuais da revolução conservadora alemã, Heidegger deixou-se embeber entusiasticamente por um pensamento negativo acerca da técnica, e o Esquecimento do Ser [Seinsvergessenheit] passou a ser um horizonte no qual enxergava o perigo latente desta forma de tecnologia que se ergue no Ocidente. Logo, a história do Ser [Seinsgeschichte] encontrara seu ponto culminante na disposição [Gestell] tecnológica (FEENBERG, 2009, p. 295). Este momento será importante e decisivo no pensamento de Heidegger pois aponta para a importância do conceito de técnica e sua constituição no pensamento político. Uma análise da compreensão do fenômeno tecnológico no pensamento de Heidegger nos fornece elementos necessários para compreender seu envolvimento com o nazismo ${ }^{20}$ (ROCKMORE, 1992, p. 238).

\subsubsection{O horizonte da neutralidade do conceito de técnica}

Primeiramente um conceito de técnica neutro que procura, assim como no conceito de verdade, buscar o que estaria como a essência da técnica, para além da mera instrumentalidade. A neutralidade do conceito inicial de técnica desenvolvido por Heidegger permite um campo fértil no qual irão tomando corpo conceitos originários da própria experiência cotidiana alemã em sua relação com a terra (enraizamento, autoctoneidade) e com o povo (destino espiritual, a ideologia Völkisch), apropriados e propagados largamente

\footnotetext{
${ }^{19}$ Heidegger wrote several essays in the 1930s on "the question concerning technology," and there is no doubt that his views on the subject were important in his initial attraction to National Socialism. Further, like the intellectuals of the Right whose enthusiasm for technology knew no limits, Heidegger believed that the Germans had a special mission to combine Technik and Kultur. For a while, he thought that the Nazis would fulfill this special mission. When he concluded instead that Hitlerism would continue the long-term process of Western domination over "being," he retreated from politics and fell into disfavor with the Nazis. His fundamental distaste for modern technology became obvious.

${ }^{20}$ The discussion of the origins and nature of Heidegger's theory of technology provides the background necessary to grasp its relation to his Nazism.
} 
pela ideologia nazista. Esta neutralidade do conceito de técnica impedira Heidegger de blindar seu pensamento acerca dos conteúdos ideológicos e raciais do nacional-socialismo. Sendo a pergunta pela essência da técnica recorrente em Heidegger. Neste marco este questionamento irá direcionar-se para a disposição (Gestell).

\subsubsection{0 horizonte do conceito de enraizamento [bodenständigkeit]}

Heidegger rejeita o que é do âmbito do cálculo e da organização (no sentido da técnica e ciência modernas) nutrindo uma simpatia profunda pelo orgânico, pelo que é enraizado [Bodenständige]. O próprio conceito de enraizamento fora utilizado amplamente pela ideologia nazista como pertencimento ao torrão natal, ao Heimat, isto toma corpo mais explicitamente na expressão Blut und Boden difundida pelo nazismo.

Heidegger foi um homem do campo. Um camponês. E fazia questão de mostrar essa ruralidade, de sempre manter "orgulhosamente viva, a sua origem rural e o seu apego à terra" (AUBENQUE, 1988; DIAS, 1997, p. 125). A esposa de Ernst Cassirer à época das conversações de Davos guardou as impressões de Heidegger como semelhantes à "um filho de camponês posto a força no interior de um castelo ${ }^{21 "}$ (SCHNEEBERGER Apud AUBENQUE, 1972, pp. 14 $15)$.

O vínculo entre a ontologia fundamental de Heidegger desenvolvida em sua Existenzphilosophie desde Ser e Tempo (1927) e a ideologia Völkisch propagada pelo nacionalsocialismo podemos encontrar no conceito romântico de enraizamento [Bodenständigkeit]. Tal conceito começa a materializar no campo da política aquilo que no estágio anterior de sua estruturação do conceito de técnica estava apenas no campo teórico. Heidegger deslocou o conceito de bodenständigkeit da condição de conceito fenomenológico-filosófico para o âmbito da prática racial, colocando-o como critério e justificativa para contenção do processo de judeização [Verjudung] ${ }^{22}$.

${ }^{21}$ [...] un fils de paysan que l'on aurait poussé de force à l'intérieur d'un chateau.

${ }^{22}$ Ainda não se sabe ao certo se Heidegger lera a infame obra Os protocolos dos sábios de Sião [Die Protocolle der Weisen von Zion, pois o tema do judaísmo global, do processo de judeização tornara-se algo de certa forma obsessivo em Heidegger e expresso nos Cadernos Negros. Peter Trawny sustenta uma tese de que o antissemitismo de Heidegger foi influenciado pela leitura de tal obra. Cf. TRAWNY, 2015, p. 162. Um dado importante: a população judaica à época da ascensão do nacional-socialismo representava $0,78 \%$ da população Alemã. Dessa forma, o argumento da existência de um grande movimento internacional judaico se revela em sua essência uma tomada de posicionamento para o lado da ideologia nazista em toda a sua estrutura, até mesmo sua exploração da ignorância, medo e ódio 
Somente um povo enraizado pode perceber sua condição ímpar e seu destino político-espiritual. Heidegger irá utilizar amplamente o conceito de enraizamento como enfrentamento ao coletivismo soviético e também ao mercantilismo norte americano e inglês que ameaçavam a Alemanha. Neste sentido, uma aproximação real e verdadeira ao nacional socialismo se dá quando Heidegger enxerga dentro da ideologia nazista esta possibilidade de enfrentamento e o conceito de enraizamento.

Neste momento, o conceito de técnica inicia uma mudança drástica, é o momento em que, sob o efeito do conceito de enraizamento e da simpatia pelo nacional-socialismo, Heidegger irá enxergar neste a possibilidade de transformação da técnica e da cultura. Uma nova técnica e uma nova ciência somente podem surgir de um povo convicto de seu papel histórico, e mais, assumir tal papel na senda de seu destino político-espiritual.

Heidegger em 1929, em uma carta para Victor Schwoerer, apontava para a compreensão de um processo de judeização. "Estamos diante da alternativa de, ou damos à nossa vida espiritual alemã forças e educadores verdadeiramente enraizados [bodenständige] em nosso solo, ou a deixamos abandonada à crescente judeização [Verjudung] em seu sentido amplo e estreito do termo ${ }^{23 \prime \prime}$ (HEIDEGGER, 1989, p. 50). O tema do enraizamento [Bodenständigkeit] persistiu no pensamento de Heidegger, ora em suas obras, ora em maior proporção em suas cartas; e esteve de forma muito explícita ligada ao processo apontado por Heidegger de judeização [Verjudung], levantando tal conceito em contraposição a tal processo, encontrando sua expressão máxima na ideologia Völkisch do nacional-socialismo. Logo, o cosmopolitismo judaico, e consequentemente, seu desenraizamento propiciaram o elo para o antissemitismo de Heidegger. A plástica e romântica ideia de um enraizamento como expressão do povo genuíno, do autóctone, irrompe no pensamento de Heidegger e se entrelaça no Blut und Boden nazista.

\subsubsection{O horizonte político situacional da Alemanha à época}

As preocupações políticas de Heidegger acerca do avanço do liberalismo e do bolchevismo influenciaram de forma expressiva o conceito de técnica moderna. 0 crescente

trabalhados e disseminados sobre a população, o que pode ser um aspecto indiciário dos interesses de Heidegger atrelados ao nacional-socialismo.

${ }^{23}$ [...] daß wir vor der Wahl stehen, unserem deutschen Geistesleben wieder echte bodenständige Kräfte und Erzieher zuzuführen oder es der wachsenden Verjudung im weiteren u. engeren Sinne endgültig auszuliefern. 
avanço das tendências internacionais do liberalismo econômico representado nos EUA e Inglaterra de um lado e o Bolchevismo Russo de outro tornam-se preocupações correntes na Alemanha, e Heidegger irá enxergar no Nazismo uma forma de combate a estas forças.

Mediante a leitura da obra de Ernst Jünger, Heidegger irá dar uma envergadura política ao conceito de técnica que até então (década de 1930) havia trabalhado sob a perspectiva da fenomenologia da facticidade. Heidegger passa então a incorporar em seu conceito de técnica elementos de situação política alemã à época como receio e rechaço das forças políticas oriundas dos EUA e Inglaterra de um lado, e de outro da União Soviética. Logo o conceito de técnica moderna de Heidegger enxerga nestas forças um elemento vinculante à ideologia nacional-socialista, a saber: a essência da técnica moderna como residindo no processo de "maquinação" perpetrado por um movimento do judaísmo global [Weltjudentum].

\subsubsection{O horizonte do antissemitismo ínsito no conceito de técnica moderna}

A constatação de um avanço de um processo de judeização presente no cerne da Alemanha que posteriormente será associado ao processo de expansão do judaísmo global. A constatação de um processo de judeização presente no cerne da Alemanha já era uma preocupação de Heidegger em 1919, expresso em cartas à sua noiva e pessoas próximas, e mais tarde irá assimilá-lo ao processo de maquinação.

Heidegger deixou-se intoxicar pela ideia de uma tecnificação global como encobrimento do Ser, o posterior atrelamento deste processo como um dos aspectos expressivos no avanço de um judaísmo mundial [Das Weltjudentum], ou seja, Heidegger vincula o cerne de tal processo, a maquinação [Machenshaft], como elemento responsável pelo avanço de uma técnica e de uma ciência aterrados ao cálculo que encontra expressão no judaísmo.

Assim como em sua crítica à decadência da metafísica Heidegger tratara de criticar Descartes e Husserl (que eram matemáticos), ao criticar a técnica moderna Heidegger vincula sua essência à espúria e difamatória crença de um movimento de dominação judaica, mediante uma técnica e ciência tipicamente judaica, baseada no cálculo, na matemática e no desenraizamento. Com uma ciência e técnica totalmente judaicas poderiam levar ao cabo o desenraizamento total e completo de todos os entes, um desenraizamento universal. 
Heidegger ataca a matemática como fundamento da metafísica, ideia que subsistiu presente na própria trajetória intelectual e científica do Ocidente. A matemática, o cálculo e a técnica eram para Heidegger elementos que apontavam para o esquecimento do Ser, de um Ser que apenas poderia ser experimentado via meditação. Filosofia é metafísica, mas não a metafisica tal qual a intelectualidade cristã subverteu alcançando seu apogeu no pensamento de Descartes e de Husserl, ou seja, na matematização do real, mas sim no pensamento meditativo no qual o povo consciente de seu destino histórico poderia concretizar, levando a cabo sua singularidade histórico-político-espiritual.

Heidegger compreende o nacional-socialismo como possibilidade de expurgo dessa técnica e de sua herança judaica, e subsequente criação de uma técnica e ciências novas totalmente "puras" por parte da universidade alemã. Porém, rapidamente irá se dar conta que ao contrário do que esperava acerca do nacional-socialismo, este incorporou a própria técnica moderna. Neste momento há um descontentamento de Heidegger em relação ao nacionalsocialismo que revela de um lado, seu pensamento contrário à técnica moderna, e de outro, contrário ao próprio nacional-socialismo enquanto prefigurado em sua forma "vulgar". O que denota que Heidegger pensara outra forma de nazismo, um nacional socialismo "essencial" ou "espiritual", que pudesse refrear o avanço das forças mercantilistas e liberais prefiguradas no americanismo e do coletivismo soviético, bem como, do processo de expansão do judaísmo global, da judeização da cultura alemã; em suma, que pudesse se colocar como resposta ao caráter desintegrador destas forças, ao desenraizamento e desintegração da província, e consigo do que havia de mais próprio ao povo alemão: a autenticidade. O mais próprio ao povo alemão era a capacidade para manifestar a verdadeira autenticidade [Eingentlichkeit], como aponta Janicaud (1990):

Em que sentido então considerar uma "verdade interna" coletiva? Na medida em que está em jogo aquilo que é mais próprio (no sentido hölderliano) O mais próprio é a capacidade de Eingentlichkeit, isto é, de autenticidade no seio de uma apropriação do possível (p. 81).

E neste sentido Heidegger em seu discurso do reitorado de Freiburg aponta para a tomada de consciência acerca do momento histórico: o irromper da revolução conservadora e, logo, do movimento nacional-socialista [Deutsche Bewegung]. Era preciso tomar parte, tornar manifesto o destino político-espiritual da Alemanha. 


\section{TÉCNICA MODERNA, DESCONTENTAMENTO E SILÊNCIO}

\subsection{A técnica moderna}

Heidegger é um pensador da essência. "Qualquer tema de Heidegger é sempre tratado a partir da questão de saber qual a essência do que se questiona, e tal essência é a do seu desvelamento (alêtheia), isto é, do seu desdobrar-se, como tempo, no movimento de vir à presença" (BELO, 2011, p. 43). Está interessado na essência das coisas, e lógico, sua aproximação ao fenomeno tecnológico irá transitar no sentido de busca pela essência de tal fenômeno, que para Heidegger, não possui nada de técnico. Em sua jornada em direção à essência da técnica, ao mesmo tempo em que procura estruturar sua critica à instrumentalidade, também, alinha a essência da técnica à matemátização e ao cálculo, que serão associados ao processo de judeização global. A primeira associação fora feita em sua crítica à essência da metafísica, que, em sua decadência, apresentava a máthesis como tal.

Para Heidegger a técnica moderna se constitui como uma forma de "desvelamento", porém, não mais como o desvelar poiético clássico grego (VERKERK, 2016, p. 216). Heidegger vincula a essência da técnica moderna para além do meramente técnico, assimilando-a assim com a essência da metafísica moderna, a saber: máthesis, o cálculo, a matematização do real.

Heidegger inicia sua trajetória em busca da essência da técnica moderna sustentando a origem desta na techné grega, para terminar apontando tal essência no processo de "maquinação" [Machenschaft] e, por conseguinte, no judaísmo global. A medida em que desenvolvera seu pensamento sobre a técnica Heidegger fora estruturando-o aparelhado aos conceitos apropriados pela ideologia nazista. Notemos que a disposição [Gestell] transformase em maquinação. O domínio da técnica no sentido exposto pela Kultukritik agora transforma-se no domínio político-econômico judaico. Heidegger é taxativo: Há uma conspiração judaica perigosa ${ }^{24}$ !

\subsection{Um destino político-espiritual do povo alemão}

Heidegger procura vincular o destino político-espiritual do povo alemão evocado por ele à metafísica, e, por conseguinte, à própria história da filosofia no Ocidente. Para isto,

\footnotetext{
${ }^{24}$ Afirmação feita durante uma conversa com Jaspers, que revela profundamente o partilhamento do antissemitismo corrente na Alemanha, e associado às explanações elucubradoras da leitura de Os protocolos dos sábios de Sião.
} 
enxerga diante de si a necessidade de expurgar a filosofia em seu fundamento das construções "espúrias" da filosofia cristã e dos filósofos judeus. Ao atacar Descartes e se propor a destruir sua filosofia Heidegger está atacando a filosofia cristã, ao passo que ao atacar o fundamento da metafisica presente na matemática está atacando seu ex-mestre Edmund Husserl do qual já nutria indignação desde a época em que era seu auxiliar (JASPERS, 1990, p. 115).

Heidegger pretendia uma nova ciência e uma nova técnica, puramente alemãs. Produzida por uma universidade forte e consciente de seu papel na consumação do destino singular do povo alemão frente a Europa e frente ao mundo. Em sua sanha de destruir a filosofia e reconstruí-la atrelando a ela o próprio destino alemão experimenta anseios antissemitas difundidos à época. Se deixa intoxicar com as ideias do desenraizamento judaico e atrela a tecnificação planetária a um movimento, fruto de um doentio surto conspiratório acerca dos textos conhecidos como "Os protocolos dos sábios de Sião", desta forma mesclamse na construção intelectual de Heidegger a ideologia antissemita de tais textos e dos sermões de Abraham a Santa Clara; o que culmina com sua compreensão de existir um movimento por ele e a maioria dos alemães à época denominado de Judaísmo global [Das Weltjudentum] que seria um dos modos de ação de uma maquinação [Machenshaft] com o intuito de domínio global, uma dominação manipuladora ${ }^{25}$.

O mesmo tom espúrio da acusação econômica utilizada por Hitler e pela propaganda nazista repetiu-se no âmbito intelectual com Heidegger ao negar a singularidade da contribuição da filosofia judaica ao mais próprio do pensamento alemão no qual até mesmo o Idealismo em suas estruturas fundamentais é debitário ${ }^{26}$. Para Heidegger tornou-se um peso enxergar a magnitude do pensamento judaico em solo alemão, assim como gradativamente viu-se diante da própria direção de uma pessoa sem sua preparação filosófica, a saber: o próprio Hitler, o que se exprime na divergência entre sua compreensão intelectualizada e estetizada de nazismo e a compreensão "fraca" e rude de Hitler.

"O engajamento de Heidegger com o movimento nazista foi profundo e sincero" (LOPARIC, 1990, p. 200), e por isso, viu na ascensão do "movimento" uma oportunidade talvez de colocar seu pensamento a serviço do nacional-socialismo, ou ao contrário, de procurar forçar, via política (Reitorado), um enquadramento do próprio nacional-socialismo no horizonte de sua filosofia, como afirma Rorty:

${ }^{25}$ Cf. TRAWNY Apud OLTERMANN. The Guardian.13 de Março de 2014.

${ }^{26}$ Cf. HABERMAS, J. Theorie und Praxis. Frankfurt am Mein: Suhrkamp, 1963. 
Heidegger queria ser o Führer intelectual da Alemanha, o dirigente ideológico da Alemanha, mais ou menos na linha de Fichte, o filósofo que tinha sido a expressão da consciência da nação. Heidegger levou esse projecto muito a sério, pensou que Hitler lhe daria uma oportunidade; enganou-se, e ao fim de um ano estava desiludido (RORTY Apud BELO, 2011, p. 06).

Habermas acusa Heidegger de se utilizar de preconceitos "platônicos" com o intuito de desvalorização da inteligência em detrimento do espírito visando reservar-se a um círculo reduzido que poderia experimentar uma verdade apofântica e esotérica.

A gota d'água, no entanto, foi o fato de o filósofo nazista recusar a responsabilidade moral e política pelas consequências de uma criminalidade de massa sobre qual poucas pessoas falavam, oito anos após o final da guerra. Na controvérsia que se seguiu, perdeu-se de vista a interpretação formulada por Heidegger para estilizar o fascismo transformando-o num destino do Ser (Seinsgeschick) pessoal (HABERMAS, 2007, p. 27).

O destino político-espiritual do povo alemão apresentou-se como uma estetização romântica de Heidegger, a partir da qual o Dasein passara a representar a coletividade do povo [Völk], um estofo no qual mesclou-se o culto ao monumental, ao heroico, à uma filosofia intoxicada por interesses pessoais ${ }^{27}$ com os objetivos do nacional-socialismo (JASPERS, 1990, p. 118). As mãos de Hitler representavam o extraordinário ${ }^{28}$ apenas na escuridão de um pensamento já turvo por uma religião sem deus, por uma metafísica violenta na espera de um "deus" ou um líder (Führer) que colocasse fim à degradação, ao baixo, ao vil, àquilo que deturparia o Ser, para o qual nada mais deveria subsistir como tal, mas ser transformado.

Diante dos diagnósticos em tom apocalíptico de Spengler, Jünger e Schmit, Heidegger não apenas compreende a técnica moderna como nociva e "devoradora", como passa a acreditar em uma missão especial da Alemanha frente ao avanço das forças destrutivas desta técnica, associada, a posteriori, com as forças do liberalismo, do bolchevismo e, principalmente, do judaísmo mundial que engloba para Heidegger estes dois últimos.

Assim, a missão especial, que se traduz em um "destino político-espiritual" [politische Geistlische Geshick] tanto da Alemanha quanto do povo alemão [Volk] seria mesclar técnica e cultura de forma a oferecer um enfrentamento às forças da técnica moderna. Heidegger

\footnotetext{
${ }^{27}$ La coincidência, en el momento, entre su concepción filosófica y sus objetivos com los objetivos nazis, por lo que es evidente que estava decididamente determinado. ${ }^{28}$ Vide nota 08, p. 06.
} 
enxergou a possibilidade de completude desta missão na instauração do nacional-socialismo. Porém, ao enxergar que o nazismo não apenas dera continuidade a uma forma de técnica semelhante à moderna se mostrara descontente e se retirou da política; porém, devemos lembrar que embora esteja para fora do âmbito político, Heidegger mantém o jargão e o ideário nazista consigo, talvez acreditando em uma forma de nazismo para além daquilo exposto pelo Führer e o partido em sua forma vulgar de nazismo. Uma das pretensões de Heidegger seria uma transformação em um nazismo essencial, espiritualizado, um nacional essencialismo tal qual descrito por Henri Meschonnic (2007). Heidegger cometeu o imperdoável erro de tentar "espiritualizar" o nazismo, dando-lhe um fundamento filosófico (DERRIDA, 1989, p. 148).

\subsection{Descontentamento e silêncio}

Aos poucos Heidegger foi apresentando um desencantamento em relação às esperanças de restauração das origens do povo alemão justamente quando o nacionalsocialismo passa a se utilizar de aparatos tecnológicos como o rádio difundido em cada vila ou povoado. Em um curto período de tempo, podemos inferir aqui os dez meses diante da Reitoria da Universidade de Freiburg, Heidegger mostrou-se descontente com o nacional socialismo justamente por que este não mais se apresentava como possibilidade de enfrentamento de uma forma, de um modus do agir técnico que era a ameaça de desenraizamento e desintegração do vilarejo, da província.

Outros fatos como o assassinato de Ernst Röhm na noite das facas longas corroboraram para a saída de Heidegger do cargo de Reitor. A partir de então, mesmo após a guerra, mesmo após a dissolução do partido nazista, Heidegger guardou sob a égide de um silêncio abismal este período de sua vida.

Algo que incomodou a todos os intelectuais do pós-guerra neste contexto foi sem dúvida o silêncio abismal de Heidegger acerca de seu engajamento no nacional-socialismo. Habermas mesmo acusando-o em alguns momentos de fascista, enxerga tal silêncio como uma "vaidade ferida" diante do fato de Heidegger se dar conta de não ser o portador da verdade, daquela verdade prefigurada pelo destino espiritual do povo alemão frente ao desvelamento do Ser e expresso no advento do nazismo em solo alemão como o tempo de decisão no qual todos teriam a responsabilidade na consumação de tal destino. O silêncio abismal de Heidegger se estendeu à sombra nefasta de Auschwitz, na qual o "Blut und Boden" veio a 
transformar-se em "Arbeit macht Frei", ou seja, onde o que era o destino do povo alemão veio a transformar-se na planificação tecnocientífica da hecatombe humana.

\section{À GUISA DE CONCLUSÃO}

Acreditamos ser o conceito de técnica desenvolvido por Heidegger um eixo, que gradativamente torna-se central em sua trajetória intelectual, bem como, um ponto importante na compreensão de seu envolvimento com o nazismo e do antissemitismo na arquitetônica de seu pensamento; e a partir de elementos ínsitos na própria crítica cultural alemã passa a se desenvolver culminando com suas reflexões e posicionamentos durante o advento da subida do nacional socialismo ao poder. Assim, há um desenvolvimento de tal conceito na direção de encontro com a ideologia nacional socialista.

Porém, apesar de ressurgida a polêmica e de expostos novamente os "ossos no armário", devemos nos guiar pela via de compreensão e de não obliteração da importância do pensamento de Heidegger para a Filosofia do século XX e corrente. Não podemos nos furtar ao reconhecimento da grandiosidade de sua obra e profundidade; mas também, não podemos ingenuamente tentar fechar os olhos em relação a seu envolvimento com o nazismo.

Talvez seja o momento de encararmos a obra de Heidegger em sua profundidade como paradoxalmente morada do perigo, mas também dotada de um caráter salvífico. É preciso separar o joio do trigo, as potencialidades e as insuficiências. Assim, tal obra se nos apresenta como desafio, ao qual devemos nos direcionar para uma compreensão mais profunda e sincera.

Nestas linhas nos propusemos a uma colaboração com uma compreensão do aspecto importante e do peso que o conceito de técnica, e principalmente do conceito de técnica moderna exercera sobre a arquitetônica do pensamento de Heidegger e sua evolução em relação a aproximação e adesão ao partido nacional socialista. Um aspecto que merece ser explorado por ser de um lado referente a um fenômeno complexo e característico do humano, a saber: o fenômeno técnico, e de outro lado, a importância desde fenômeno e seu desenvolvimento no interior do pensamento de um dos maiores expoentes da filosofia do século $X X$.

A polêmica às voltas ressurge, não podendo mais ser dissociado este aspecto horrível do nome de Heidegger, porém, uma senda se abre diante de nossos pés, restando-nos assumir 
a responsabilidade de nossas leituras a partir deste aspecto indelével e não menos importante da vida e obra deste mestre paradoxal.

\section{REFERÊNCIAS}

AUBENQUE, P. Encore Heidegger et le Nazisme. In: Le Débat: Paris, 1988.

Ernst Cassirer - Martin Heidegger: Débat sur le Kantisme et la Philosophie

(Davos, mars 1929). Éditions Beauchesne: Paris, 1972.

BELO, F. Heidegger: Pensador da Terra. Covilhã - Portugal. Coleção LusoSofia, 2011.

BORGMANN, A. Technology. In: Dreyfus, H. \& Wrathall, M. (2005). A Companion to Heidegger. Oxford: Blackwell, 2005.

DERRIDA, Jacques. Del Espíritu: Heidegger y la pregunta. Editorial Pré-Textos: Valencia, 1989.

DIAS, M. P. Cassirer - Heidegger. O encontro de Davos ou o debate sobre Kant e a modernidade. Philosophica. nr.10: Lisboa, 1997, pp. 121-143.

FÉDIER, François. Heidegger: Anatomie d'un scandale. Paris: Éditions Robert Laffont, 1988.

FEENBERG, A. From essentialism to Constructivism: Philosophy of Technology at the Crossroads. In: HIGGS, E.; LIGHT, A.; STRONG, D. Technology and the Good Life? 5. Ed. Chicago: Chicago University Press, 2009.

FRAGOZO, F. Crítica da técnica, crítica da filosofia: Heidegger e Simondon. In: Rev. Filos., Aurora, Curitiba, v. 24, n. 35, p. 509-528, jul./dez. 2012.

GUNKEL, D. \& TAYLOR, P. Heidegger and the Media. Cambridge: Polity, 2014.

HABERMAS, J. Entre Naturalismo e Religião: Estudos Filosóficos. Rio de Janeiro: Tempo Brasileiro, 2007.

\& Weill, N. (entrevistador). Habermas: L'Europe actuelle entre la paralysie et la distraction. Le Monde. Paris, 07 novembro 2014. Disponível em: <http://www.lemonde.fr/idees/article/2014/11/07/habermas-I-europe-actuelleentre-la paralysie-et-la-distraction 4520274 3232.html>. Acesso em: 05/03/2017. HEIDEGGER, M. Brief an Victor Schwoerer vom 02.10.1929. In: Sieg, Ulrich. Die Verjudung des deutschen Geistes. Die Zeit. nr. 52 vom 22. Dezember 1989.

Lógica: A pergunta pela essência da linguagem. Lisboa: Fundação Calouste Gulbenkian, 2008.

The Self-Assertion of the German University and The Rectorate 1933/34:

Facts and Thoughts. Review of Metaphysics, 38:3, Mar, 1985.

Überlegungen II -VI (Schwarze Hefte 1931 - 1938) Gasamtausgabe 94.

Frankfurt am Main: Vittorio Klostermann, 2014. 
HERF, J. Reactionary Modernism: Technology, Culture and Politics in Weimar and Third Reich. Cambridge: Cambridge University Press, 1998.

JANICAUD, D. A sombra deste pensamento: Heidegger e a questão política. Lisboa: Instituto Piaget, 1990.

JASPERS, K. Notas sobre Heidegger. Madrid: Mondadori, 1990.

Philosophische Autobiographie. Erweiterte Neuausgabe: Munich: Piper, 1977.

LÉVINAS, E. Entre nós: Ensaios sobre alteridade. Petrópolis: Editora Vozes, 1997.

LOPARIC, Z. Heidegger Réu: Um ensaio sobre a periculosidade da Filosofia. Campinas: Papirus Editora, 1990.

MESCHONNIC, H. Heidegger ou le national essencialisme. Éditions Laurence Teper, 2007.

OLTERMANN, P. Heidegger's 'black notebooks' reveal antisemitism at core of his philosophy: New publication shows highly influential philosopher saw 'world Judaism' as driver of dehumanising modernity. The Guardian. Londres, 13 março 2014.

Disponível

em:

<https://www.theguardian.com/books/2014/mar/13/martin-heidegger-black-

notebooks-reveal-nazi-ideology-antisemitism>. Acesso em 05/03/2017.

RADLOFF, B. Heidegger and the Question of National Socialism: Disclosure and Gestalt. Toronto: University of Toronto Press, 2007.

ROCKMORE, T. On Heidegger's Nazism and Philosophy. Berkeley: University of California Press, 1992.

TRAWNY, P. Heidegger y el mito de la conspiración mundial de los Judíos. Barcelona: Herder, 2015.

VERKERK, M. J; HOOGLAND, J.; VAN DER STOEP, J.; DE VRIES, M. J. J. Philosophy of Technology: An Introduction for Technology and Business Students. New York: Routledge, 2016.

ZIMMERMAN, M. Heidegger's confrontation with modernity: technology, politics, and art. Bloomington and Indianapolis: Indiana University Press, 1990.

Doutorando do Programa de Pós-Graduação em Filosofia da Universidade do Vale do Rio dos Sinos (UNISINOS) Professor Assistente de Filosofia na Universidade Federal do Piauí (UFPI) E-mail: mauriciofernandes@ufpi.edu.br 